\title{
ON CERTAIN COEFFICIENT INEQUALITIES FOR MULTIVALENT FUNCTIONS
}

\section{T. N. Shanmugam, Shigeyoshi Owa, C. Ramachandran, S. SIVASUBRAMANIAN AND YAYOI NAKAMURA}

Abstract. In the present investigation, the authors obtain sharp upper bounds for certain coefficient inequalities for linear combination of Mocanu $\alpha$-convex $p$-valent functions. The results are extended to functions defined by convolution.

Mathematics subject classification (2000): Primary 30C45, 30C50; Secondary 30C80.

Keywords and phrases: Analytic functions, starlike functions, convex functions, Mocanu $\alpha$-convex $p$-valent functions, subordination, Hadamard product (or convolution).

\section{REFERENCES}

[1] R. M. Ali, V. Ravichandran and N. Seenivasagan, Coefficient bounds for p-valent functions, to appear.

[2] F. R. KeOGh AND E. P. Merkes, A coefficient inequality for certain classes of analytic functions, Proc. Amer. Math. Soc., 20 (1969), 8-12.

[3] W. Ma And D. Minda, A Unified treatment of some special classes of univalent functions, in: Proceedings of the Conference on Complex Analysis, Z. Li, F. Ren, L. Yang, and S. Zhang(Eds.), Int. Press (1994), 157-169.

[4] D. V. Prokhorov And J. Szynal, Inverse coefficients for $(\alpha, \beta)$-convex functions, Ann. Univ. Mariae. Curie-Sklodowska Sect. A, 35 (1981), 125-143.

[5] V. Ravichandran, Metin Bolcal, Yasar Polotoglu and A. Sen, Certain Subclasses of Starlike and Convex functions of complex order, Hacet. J. Math. Stat., 34 (2005), 9-15.

[6] T. N. Shanmugam and S. Sivasubramanian, On the Fekete-Szegó problem for some subclasses of analytic functions, J. Inequal. Pure Appl. Math., 63 (2005), Art.71, 6 pp. (electronic).

[7] H. M. SRivastava And A. K. Mishra, Applications of fractional calculus to parabolic starlike and uniformly convex functions, Computer Math. Appl., 39 (2000), 57-69. 